\title{
Erzurum Kenti Yüzüncüyıl Parkı Örneğinde Kent Parklarındaki Gürültü Kirliğinin Mevcut Durum Analizi
}

\begin{tabular}{l|c}
\hline Araştırma / Research & \\
Gelis Tarihi / Received & Serkan ÖZER \\
05.09.2017 & \\
Kabul Tarih / Accepted & Atatürk Üniversitesi Mimarlıve Tasarım Fakültesi Peyzaj Mimarlı̆̆ \\
$\begin{array}{l}\text { 13.10.2017 } \\
\text { DOI }\end{array}$ & Bölümü, Erzurum- Türkiye \\
10.28955/alinterizbd.336799 & e-posta: sozer2000@hotmail.com \\
ISSN 2564-7814 & \\
e-ISSN 2587-2249 & \\
\hline
\end{tabular}

Öz: Gürültü kirliliği kentlerdeki önemli çevre sorunlarından birisi haline gelmiştir. Özellikle araç sayısının artması ile beraber gürültü kirliliği de artmaktadır. İnsanların kentin rahatsız edici ortamından kaçarak sığındıkları kent parkları da maalesef gürültü kirliliğinin baskısı altındadır. Özellikle kent merkezlerinde bulunan parklar daha büyük baskı altındadır. Çalıma ile Erzurum kenti merkezinde bulunan Yüzüncüyıl Parkı'ndaki gürültü düzeyi belirlenmeye çalışılmıştır. Parkta sabah, öğle ve akşam yapılan ölçümler sonucunda; gürültü kirliliğinin ortalama olarak 66,62 dB(A)'ya akșam vaktinde ise 68,75 'ya ulaştığ değerlerin Gürültü Kontrol Yönetmeliği’nce izin verilen sınır değerlerini $25 \mathrm{~dB}(\mathrm{~A})$ 'dan daha fazla aştığı tespit edilmiştir. Özellikle Parkın 5. Ölçüm yerinde akşam vaktinde gürülttü düzeyinin 73,63 dB(A)'ya kadar çıktığı belirlenmiştir. İstatistiki olarak ta $(\mathrm{p}<0.01)$ sabah, öğle ve akşam gürültü değerleri arasındaki fark önemsiz bulunmuştur. Ayrıca çalışmada, parktaki gürültü kirliliğinin azaltılmasına yönelik bazı çözüm önerileri verilmiştir.

Anahtar Kelimeler: Gürültü kirliliği, Yüzüncüyıl Parkı, önlem, bitki, Erzurum

\section{Present Situation Analysis of Noise Pollution in City Parks of Erzurum in the Sample of Yüzüncüyıl Park}

\begin{abstract}
Noise pollution has turned out to be one of the most important environmental matters in urban areas. Depending especially on the increase in the number of motor vehicles severity of noise pollution also increases. City parks, where people shelter going away from uncomfortable urban environment are under the pressure of noise pollution, which is larger in city parks established in especially city centres. This study is aimed to determine noise levels in a city park established in Erzurum city centre, Yüzüncüy1l Park. It was found in the study that mean noise level was $66.62 \mathrm{~dB}(\mathrm{~A})$ and $68.75 \mathrm{~dB}(\mathrm{~A})$ in the morning and evening, respectively. These values were determined to exceed $25 \mathrm{~dB}(\mathrm{~A})$ allowable limit values in Noise Control Regulation. At especially measurement point 5 in the park, noise level in the evening reached up $73.63 \mathrm{~dB}(\mathrm{~A})$. Differences between noise values were found to be statistically insignificant $(\mathrm{p}<0.01)$ in the morning, at noon and in the evening. In addition, some solution proposals are presented in the study to reduce noise levels in the park.
\end{abstract}

Keywords: Noise pollution, Yüzüncüyıl Park, barrier, plant, Erzurum

\section{GİRIS}

Gürültü kirliliği günümüzde kentler için giderek artan bir çevre sorunu olarak karşımıza çıkmaktadır. Araç sayısındaki hızlı artış gürültü düzeyinde de hızlı artışa neden olmaktadır. Eskiden konut yerleşimlerinin ana ulaşım arterlerine veya ana caddelere yakın olması mülkün değerinde bir artış sağlarken, bugün artık gürültüden uzak, sessiz tali yollardaki konut yerleşimleri rağbet görmektedir (Yılmaz ve Özer, 2001).

Gürültü kirliği insanlarda değişik sağlık sorunlarına neden olmaktadır. Gürültüye maruz kalma süresine ve şiddetine bağlı olarak, insan sağlığına üzerine etkileri dört ana şekilde olmaktadır. Bu etkiler; duyma sorunları gibi fiziksel etkiler; kan basıncının yükselmesi, kalp ritminin düzensizleşmesi ve ülser gibi fizyolojik etkileri; sinirlilik, huzursuzluk ve stres gibi psikolojik etkiler ile duymadaki 
azalma ve duyulan şeyi yanlıș anlama gibi performans üzerine etkiler olarak sıralanabilir. (Job, 1996: ${ }^{\circ}$

Evans, Hygge, 2000: Stansfeld, 2000: Passchier-Vermeer, Passchier, 2000: Marius ve ar., 2005).

Kentlerde gürültüsüz yerler yok denecek azdır. Ancak parklar özellikle gürültünün olmadığı veya en az olması gereken yerlerden birisidir. Kent merkezleri ve ana trafik yollarındaki parklarda gürültü kirliliği önemli bir sorun olmaktadır (Zannin vd, 2006).

Gürültü kirliliğinin belirlenmesi ve önlenmesi için Türkiye'de çok sayıda çalışmalar yapılmaya başlanmıştır (Uslu ve Yücel, 1997: Atmaca ve Peker, 1997: Yılmaz ve Özer, 2005: Selim vd, 2011). Gelişmiş ülkelerdeki gelişmelere paralel olarak, Türkiye'de de değişik kurumlar tarafından gürültü eylem planlarının hazırlanmaya başlandığı görülmektedir (Anonim, 2008: Anonim, 2010a; Anonim, 2010b).

Bu çalışmada, Erzurum kentinin çok önemli bir konumunda bulunan Yüzüncüyıl Parkı'nın gürültü düzeyinin belirlenmesi ve gürültü kirliliğine karşı park özelinde ve genel olarak alınacak önlemler belirtilmiştir. Ayrıca araştırma, Türkiye'de parklardaki gürültü düzeyinin mevcut durumunun ortaya konması amacıyla pek fazla çalışma yapılmamış olması nedeniyle önem arz etmekte ve diğer çalışmalar için yol gösterci özelliği ile de ön plana çıkmaktadır.

\section{MATERYAL VE YÖNTEM}

Materyal

Erzurum Kenti 1850 rakımda kurulmuş olup, kentin nüfusu 2017 yılı itibari ile 417.385 kişidir (Anonim, 2017). Kent ekonomisinin temelini kış turizmi, tarım-hayvancılık ve hizmetler sektörü oluşturmaktadır.

Çalışma alanı olan Yüzüncüyıl Parkı 31,3 da alan kaplamaktadır. Erzurum’un önemli bir alanında bulunan Yüzüncüyıl Parkı kentin batı girişinde yerleşim yerleri, resmi daireler, şehir merkezi ve üniversite arasında bulunmaktadır. Park ayrıca kentin batı girişinde olup, kent merkezinden batıdaki kentlere, üniversiteye, Artvin ve kuzey ilçeler ile Terminal Caddesi'ni takiben Şehirlerarası Otobüs Terminali, Havaalanı ile Çevre Yoluna giden araçların kullandığı yoğun bir trafik arasında bulunmaktadır.Park bakımlı olmamasına rağmen konumundan dolayı oldukça fazla sayıda insan tarafindan tercih edilmektedir.

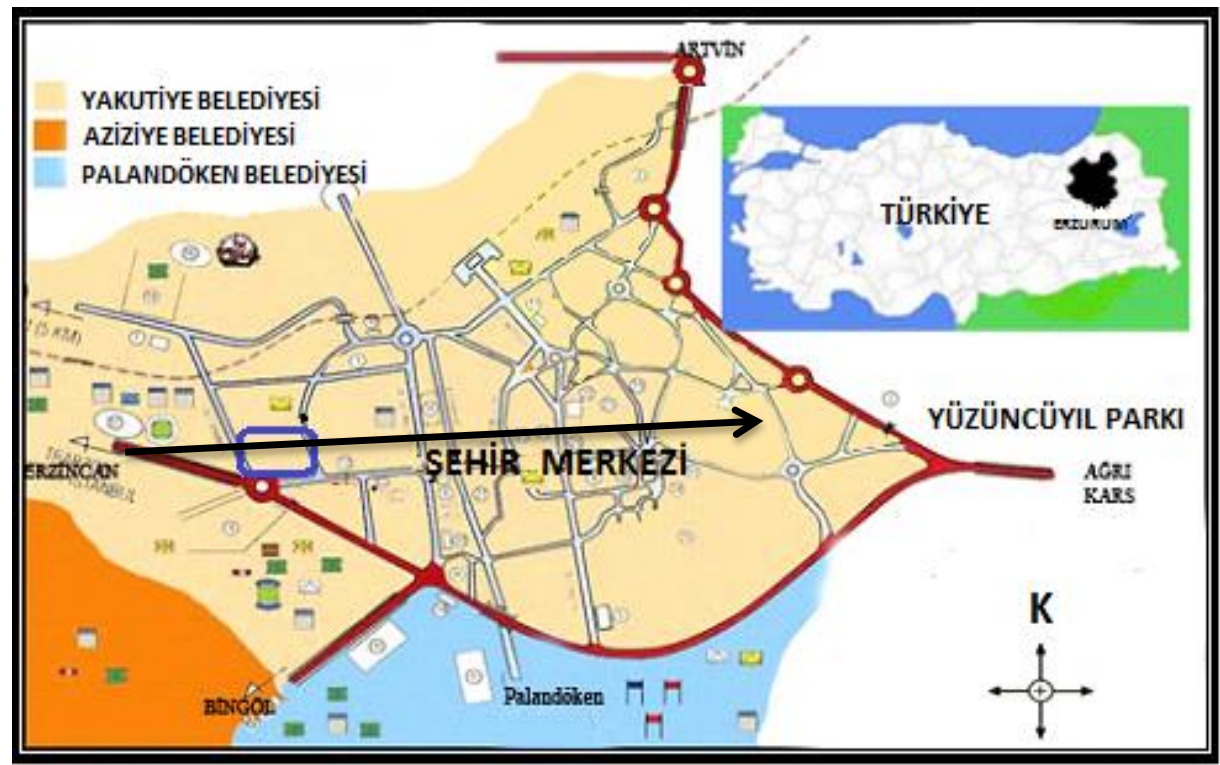

Şekil 1. Yüzüncüyıl Parkı’nın konumu

\section{Yöntem}

Çalışmada öncelikle gerek gürültü kirliliği gerekse de çalışma alanı hakkında veri toplaması ve değerlendirmesi yapılmıştır. Gürültü ile ilgili daha önce yapılan çalışmaların yöntemleri incelenmiştir (Özer vd, 2009: Szeremeta vd, 2009: Rajiv ve Yogesh, 2012: Merchan ve Balteiro, 2013. Valentin ve Sorin, 2013). 
İkinci aşamada çalışma alanı olan Yüzüncüyıl Park’ında Pazartesi, Çarşamba ve Cumartesi günleri sabah öğle akşam saatlerinde ölçümler yapılmıştır (Şekil 2). Ölçümler sabah 10:00-11:00, öğlen 14:00-15:00 ve akşam 18:00-19:00 saatleri arasında yapılmıştır. Parkta toplam 9 saat boyunca 72 kez ayrı ölçüm yapılmıştır. Kentin soğuk iklim şartları nedeniyle gece saatlerinde parkların pek fazla tercih edilmemeleri nedeniyle göz ardı edilmiştir.

Ölçümler Sonometre ile (CEL $254 \mathrm{~K} 2, \pm 1$ duyarlılıklı) ile yerden yaklaşık $1.20 \mathrm{~m}$ yükseklikten yapılmıştır. Ölçümler yağmursuz ve rüzgârsız günlerde (Anonim, 2010a), parkı homojen bir şekilde kaplayacak şekilde parkın kenarları ve ortasından olmak üzere 8 ayrı noktasından 4 dakika boyunca 40 değer alınarak eşdeğer Gürültü Seviyesi olan Leq’e çevrilmiştir.

$$
\text { Leq }=10 \log 1 / 10 \sum_{i=1}^{n} 10^{L i / 10}
$$

Formülde 1;

Leq: Eşdeğer gürültü düzeyi (dBA)

$\mathrm{n}=$ Gürültü ölçüm sayısı

$\mathrm{Li}=$ Ölçümdeki gürültü düzeyi

Böylece parkın tek noktasından 480 olmak üzere, park için toplam 1920 değer alınarak gürültü düzeyi belirlenmiştir. Bu değerler SPSS paket programı kullanılarak varyans analizine tabi tutulmuş ve önem durumları incelenmiştir.

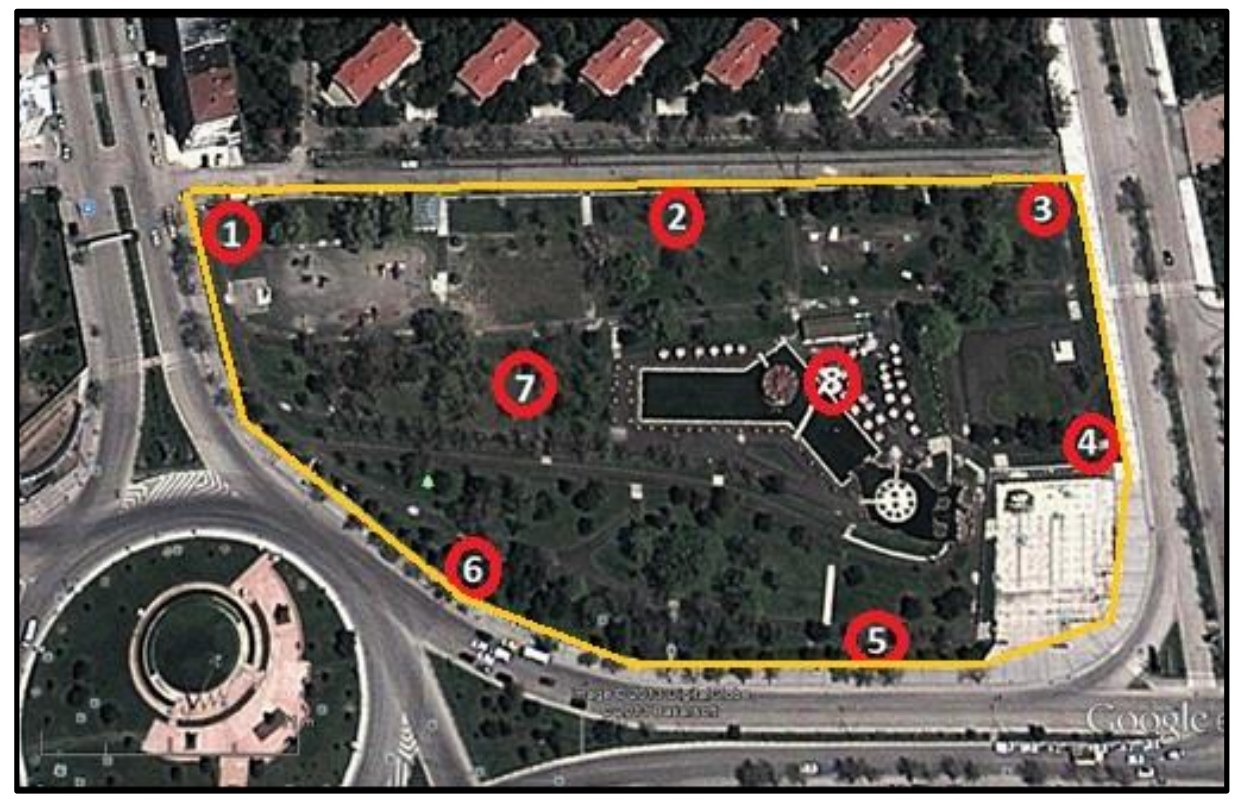

Şekil 2. Yüzüncüyıl Parkı’ndaki gürültü ölçüm yerleri

Çalışmanın son aşamasında ise bu parktaki gürültü düzeyinin ISO ve Gürültü Kontrol Yönetmeliğinin izin verdiği değerleri aşması durumunda alınabilecek önlemler belirtilmiştir.

\section{ARAŞTIRMA BULGULARI VE TARTIŞMA}

Gürültü kirliliği kentlerde insanlar için artık önemli çevre sorunu haline gelmiştir. Kentlerdeki gürültü ve diğer çevre sorunları insanları doğal veya doğala yakın ortamlar olan parklara gitme isteklerini ortaya çıkarmaktadır. Ancak parklar da artık gürültü kirliliğinin yoğun baskısı altındadır.

Yüzüncüyıl Parkı'nda da büyük boyda çok sayıda ağaçlar bulunmaktadır. Parkta daha çok Acer negudo L. (Akça ağaç), Ulmus glabra L. (Karaağaç), Pinus sylvestris L. (Sarıçam), Fraxinus exelcior L. (Adi dişbudak), Betula verrucosa L. (Huş Ağacı) bulunmaktadır. Parkta çalı olarak ise sadece Symphoricarpos albus L. (İnci çalısı) tespit edilmiştir. Parkın kenarında ise gürültü bariyeri teşkil edecek çalı, ibreli ve yapraklı ağaç varlığı yoktur. Bu yüzden yollardaki yoğun trafik gürültüsü park içinde de hissedilmektedir. Parkta kent merkezinden gelen güney kısmından kuzeye doğru ilki hemen parkın kenarında olmak üzere $2,5 \mathrm{~m}, 1,5 \mathrm{~m}$ ve $2 \mathrm{~m}$ olan üç adet kademeli kot düşüşü bulunmaktadir. 
Belirtilen üç kot ile sağlanan 6 m'lik düşüş farkı yoğun gürültünün belirli oranda azalmasına yardımcı ${ }^{\circ}$ olmaktadır. Ancak buna rağmen Yüzüncüyıl Parkı önemli araç yollarının kesişim noktasında bulunmasından dolayı oldukça yüksek gürültü kirliliğine maruz kalmaktadır. Parkının ortalama gürültü değeri 66,62 dB(A) olarak belirlenmiştir. En yüksek gürültü akşam vaktinde 68,75 dB(A), en düşük ise $65,36 \mathrm{~dB}(\mathrm{~A})$ ile sabah vaktinde belirlenmiştir. Parktaki en düşük değerler 2. ölçüm yerinde belirlenmiş ve bu noktada öğlen 57,68 dB(A)'lık değer kaydedilmiştir. 2. Ölçüm yeri parkın trafik yollarından uzak DSİ'nin bahçesi ile sınır noktasında olmasından dolayı düşük çıkmıştır. Buna rağmen yine de gürültü düzeyi oldukça yüksek çıkmıştır. Yine parktaki ölçümlerde en yüksek gürültü düzeyi ise 73,63 $\mathrm{dB}(\mathrm{A})$ ile akşam 5. ölçüm yerinde belirlenmiştir (Çizelge 1). Bu alanın iki yolun birleştiği ve yola yakın bir konumda olmasından dolayı gürültü düzeyini yüksek çıkmıştır.

Oysa ISO ve Türkiye'de geçerli olan Gürültü Kontrol Yönetmeliği’ne (Anonim, 2012) göre hassas ve duyarlı alanlar içinde olan parklarda olması gerekli gürültü düzeyi $45 \mathrm{~dB}(\mathrm{~A})$ olarak verilmiştir. Sabah öğlen ve akşam gürültü düzeylerinin izin verilen değerin yaklaşık $20 \mathrm{~dB}(\mathrm{~A})$ 'den daha fazla çıkması parktaki gürültü düzeyinin fazlalığını göstermektedir.

Çizelge 1. Yüzüncüyıl Parkı'nın ölçüm yerlerindeki gürültü değerleri dB(A).

\begin{tabular}{ccccc}
\hline Ölçüm Yeri & Sabah & Öğle & Akşam & Ortalama \\
\hline 1 & 63,66 & 66,17 & 69,91 & 66,58 \\
\hline 2 & 58,23 & 57,68 & 59,98 & 58,63 \\
\hline 3 & 70,02 & 69,88 & 69,02 & 69,64 \\
\hline 4 & 71,13 & 68,44 & 69,24 & 69,60 \\
\hline 5 & 69,36 & 68,44 & 73,63 & 70,48 \\
\hline 7 & 68,78 & 69,12 & 71,78 & 69,89 \\
\hline 8 & 61,74 & 64,21 & 69,03 & 64,99 \\
\hline Ortalama & 59,98 & 62,05 & 67,38 & 63,12 \\
\hline
\end{tabular}

İstatistiki olaraksa $\mathrm{P}<0.01$ göre sabah öğlen ve akşam gürültü değerleri arasında önemli bir sonuç çıkmamıştır.

\section{SONUÇ VE ÖNERILER}

Kent merkezlerinde bulunan parkların çevresi önemli ve yoğun araç yolları ile çevrilmiştir. Parklardaki gürültü düzeyinin artmasına neden olan araç yoğunluğu, parkların konforunun azalmasına ve gelen kişilerin parktan aldıkları huzurun azalmasına neden olmaktadır. Bu parklara örnek olarak Erzurum Kenti Yüzüncüyıl Parkı verilebilir.

Yüzüncüyıl parkındaki gürültü sorununun belirlenmesi amacıyla parkta yapılan ölçümler sonucunda, ISO ve Gürültü Kontrol Yönetmeliği'nce izin verilen sınır değerlerini oldukça aştığı tespit edilmiştir. Yapılan ölçümlerde parktaki gürültünün, izin verilen sınır değeri olan $45 \mathrm{~dB}(\mathrm{~A})$ 'yı ortalama 21,62 $\mathrm{dB}(\mathrm{A})$ geçtiği belirlenmiştir. Yine 5. ölçüm yerinde akşam vaktinde ise 28,63 $\mathrm{dB}(\mathrm{A})$ gibi yüksek bir rakam ile aşması gürültü kirliliğinin parktaki ulaştığı düzeyi göstermektedir.

Parktaki gürültünün sebebi önemli yollar ile çevrilmiş olması ve yoğun araç trafiği olmaktadır. Özellikle parkın doğu kısmında araç yolunun yukarı eğimin olması ve araçların bu kısımda devirlenmesi sonucu parka etki eden gürültü düzeyinin artmasına neden olmaktadır. Ayrıca doğu ve batı kısmında gürültüye karşı herhangi bir bariyerin olmaması parktaki gürültü düzeyinin artmasına neden olmaktadır. Bunun için yapılabilecek en iyi çözüm parkta gürültüye karşı önlemler almaktır (Anonim, 2013). Parkın en çok araç yoğunluğuna ve gürültü baskısına maruz kalan güney kısmının yol seviyesinden kotunun yaklaşık 2,5 m düşük olmasından dolayı gürültü azaltmaktadır. 
Parkın kuzey yönü hariç yapılacak iyi bir canlı ve cansız bariyer kombinasyonu ile gürültü düzeyi azaltılabilir. Cansız bariyer olarak estetik bir duvar, toprak yığılarak park kenarının yükseltilmesi veya park kotunun düşürülerek bu alana gürültüye karşı etkili olan çalıları ağaççık ve ağaçlar ile desteklemektir. Ağaç ve çalıların yerden sık dallanan, büyük ve sert yapraklı, sık yapraklı ses yönüne dik duran yaprak yapısına sahip, özellikle ibreli ve yüksek boylu olmaları gerekmektedir (Alparslan, 1987: Harris, 1986: Walker, 1991: Yücel, 1995). Özer vd. (2008)'da yaptığı çalışmada da yol kenarlarında bitkisel önlemler önermiş ve özellikle Pinus sylvestris L. (Sarıçam)'yi hem etkili olmaları hem de ibreli olması nedeniyle tüm yıl etkili olmasından dolayı Erzurum kentinde kullanmaları tavsiye edilmiştir.

Günümüzde parklar yapılırken daha çok estetik ve fonksiyonel özellikleri düşünülmektedir. Oysa yapılan tüm çalışmalar daha çok kişilerin konforunun sağlanması içindir. Ancak konfor söz konusu olunca gürültü kirliliği olan bir yerde yeterince konforun olması mümkün değildir. Bu yüzden de park tasarımında veya mevcut parklarda parkın gürültü kirliliği de dikkate alınmalıdır. Parkın çevresinde gürültü bariyeri ile yapılacak iyi bir düzenleme çözüm olabilir. Ayrıca planlama boyutu ile eğitsel ve yasal yönden de alınabilecek önlemler ile gürültü kirliliğinin azaltılmasında başarılı olma ihtimali artacaktır (Gaja vd, 2003: Ramis vd, 2003). Parkları yapan belediyelerin ve kullanan kişiler olan halkın bu konuda bilinçlendirilmesi de çok önemli bir unsur olduğu unutulmamalıdır.

\section{KAYNAKLAR}

Alparslan, E., 1987. Karayollarında Gürültüye Karşı Peyzaj Mimarlığı Açısından Alınabilecek Önlemler. Dokuz Eylül Üniv. Mühendislik ve Mimarlık Fak. Şehir ve Bölge Planlama Bölümü, Semineri, s,13

Anonim, 2008. Adana Büyükșehir Belediyesi, Adana İli Trafik Gürültüsü Eylem Planı.

Anonim 2010a. Gürültü Kontrol Çalışmaları, T.C. Çevre ve Orman Bakanlığı, Ankara, Temmuz.

Anonim, 2010b. Çevresel Gürültünün Değerlendirilmesi ve Yönetimi Yönetmeliği, Resmi Gazete, Say 27601.

Anonim, 2012. http://www.mevzuat.gov.tr/Metin.Aspx?MevzuatKod=7.5.14012\&Mevzuat Iliski=0\&sourceXmlSearch $=$

Anonim, 2017. (http://www.erzurum.gov.tr/nufus.asp).

Anonim, 2013. http://www.mimarlikdergisi.com/index.cfm?sayfa=mimarlik\&DergiSayi=7\&Rec ID=136

Atmaca, E., ve Peker, İ., 1999. Sivas'ta Trafik Gürültüsü. Ekoloji Dergisi, 8 (30), 3-8.

Evans, G.W, Hygge, S., 2000. Noise and Performance in Children and Adults. In D. Prasher (Ed.), Handbook of Noise and Health.

Gaja, E., Gimenez, A., Sancho, S., and Reig, A., 2003. Sampling Techniques Fort The Estimation of The Annual Equivalent Noise Level Under Urban Traffic Condition. Applied Acoustics, 64 (1), 43-53.

Harris, R.A., 1986. Vegatative Barriers: An Alternative Highway Noise Abatement Measure. Noise Control Engineering Journal, 27 (1), 34-48.

Job, R.F.S., 1996 The Influence Of Subjective Reactions to Noise on Health Effects of The Noise. Environmental International, 22 (1), 93-104.

Merchan, I.C., and Balteiro, L.D., 2013. Noise Pollution Mapping Approach and Accuracy on Landscape Scales. Science of The Total Environment. Vol. 449, p.115-125.

Marius, A., Tijunelis, M.D, Fitzsullivan, B.A, Sean, O., Henderson, M.D., 2005. Noise in the ED. The American Journal of Emergency Medicine. 23(3), 332-335.

Ozer, S., Irmak, M.A., Yılmaz, H., 2008. Determination of Roadside Noise Reduçtion Effectiveness of Pinus sylvestris L. and Populus nigra L. in Erzurum, Turkey. Environmental Monitoring Assessment, 144, 191197.

Ozer, S., Yeşil, M., Yılmaz, H., ve Yeşil, P., 2009. Evaluation and Analysis of Environmental Motorway Noise Pollution in The City of Tokat, Turkey. Scientific Research and Essay 4 (11), 1205-1219.

Passchier-Vermeer, W., Passchier, W.F., 2000. Noise Exposure and Public Health. Environmental Health Perspectives Supplements, 108 (1), 123-131.

Rajiv, B.H., and Yogesh, P.B., 2012. Assessment Of Noise Pollution Indices in The City Of Kolhapur, India. International Conference On Emerging Economies - Prospects and Challenges, Book Series: Procedia Social and Behavioral Sciences Vol. 37, 448-457.

Ramis, J., Alba J., Garcia, D., and Hernandez, F., 2003Noise Effects of Reducting Traffic Flow Through A Spanish City. Applied Acoustics, 64 (3), 343-364.

Stansfeld, S., Haines, M., Brown, B., 2000. Noise and Health in The Urban Environment. Reviews of Environmental Health, 15, 43-82.

Szeremeta, B. and Zanin, H.P.T., 2009. Analysis and Evaluation of Soundscapes in Public Parks Through Interviews and Measurement of Noise. Science of the Total Environment. 407, 6143-6149.

Selim, T., Yörüklü, N., Yılmaz, E., İlker, A., 2011. Karayolu Gürültü Haritası Hazırlama Projesi, TMMOB Harita ve Kadastro Mühendisleri Odas1, 13. Türkiye Harita Bilimsel ve Teknik Kurultay1, Ankara, 18-22 Nisan 2011.

Urban, J., and Maca, V., 2013. Linking Traffic Noise, Noise Annoyance and Life Satisfaction: A Case Study. International Journal of Environmental Research and Public Health, 10 (5), p 1895-1915. 

Uslu, C., ve Yücel, M., 1997. Adana Kentinde Gürültü Kirliliği Üzerine Bir Araştırma. Ekoloji Dergisi, 7 (25), 9- Alınterı

Walker, D.D., 1991. Planting Design. Van Nastrand Reinhob. New York, USA, p. 196.

Valentin, P., and Sorin, B., 2013. Research on Noise Pollution in Densely Populated Urban Areas Environmental Engineerıng and Management. 12 (2), 409-415.

Y1lmaz, H., and Ozer, S., 2005. Evaluation and Analysis Of Environmental Noise Pollution in The City of Erzurum, Turkey, International Jorunal of Environment and Pollution, 23 (4), pp. 438-448.

Yılmaz, H., ve Özer, S., 1997. Gürültü Kirliliğinin Peyzaj Planlama Yönünden Değerlendirilmesi ve Çözüm Önerileri. Atatürk Üniversitesi Derg., 28 (3), 515-531.

Yılmaz, H., ve Özer, S., 2001. Erzurum Kenti Gürültü Kirliliğine Karşı Halkın Duyarlılığı Üzerine Bir Çalışma. Atatürk Üniversitesi Derg., 32 (3), 321-327.

Yücel, M., 1995. Çevre Sorunları. Çukurova Üniv. Ziraat Fak. Ders Kitabı, Yayın No:150, Adana.

Zannin, H.P.T., Ferreira, A.M.C., and Szeremeta, B., 2006. Evaluation of Pollution in Urban Parks. Environmental Monitoring and Assessment, 118, 423-433. 